\title{
Influence of profilin on sensitisation (1) CrossMark profiles determined by cutaneous tests and lgE to major allergens in polysensitised patients
}

\author{
Nieves Segura', Teresa Abos², José A. Compaired ${ }^{3}$, Esther Compés ${ }^{4}$, Isabel Guallar ${ }^{5}$, Manuel Morales ${ }^{1}$, \\ Susana Monzón ${ }^{6}$, José Mozota7, Pilar Muñoz , Jesús Pola9 , Macarena Quintana7, Beatriz Rojas ${ }^{8}$, Sara San Juan7, \\ Felicitas Villa ${ }^{1}$, Cristina Zapata ${ }^{9}$, Lucía Jimeno ${ }^{10}$ and Fernando de la Torre ${ }^{10^{*}}$
}

\begin{abstract}
Background: Profilin sensitisation is considered a diagnostic confounding factor in areas where patients are exposed to multiple pollens. The aim of this study is to assess pollen sensitisation profiles in adults and children and to evaluate, by means of component-resolved diagnosis (CRD) and skin prick testing (SPT), which pollens may be considered as risk factors of profilin sensitisation in order to establish the best diagnostic approach in polysensitised patients.

Methods: A total of 231 pollen-allergic patients (adults and children) were included, out of the pollen season, from an area with similar levels of pollen exposure. Allergological diagnosis was performed by SPT and determination of specific IgE (slgE) to major allergen components (ADVIA-Centaur ${ }^{\mathrm{TM}}$ ). Patients had not received immunotherapy in the last 5 years and had to reside in the area for 5 consecutive years before entering the study.

Results: The relation between sensitisation measured by SPT and by slgE was studied using a model of cases (patients with +slgE to a specific allergen) and controls (patients with -slgE to the same allergen). The outcome, in terms of odds-ratios (OR), was statistically significant for Olea (Ole e 1) $(p=0.0005)$, Salsola (Sal k 1) $(p=0.0118)$ and Platanus (Pla a 1+2) $(p=0.0372)$. While positivity of SPT to most pollens was statistically associated with a risk of profilin sensitisation, by CRD the association was statistically significant only for Ole e 1 (OR 3.5, Cl 95 \%, 1.6-7.6, $\mathrm{p}=0.0014)$, and Phl p 5 (OR 11.9, Cl $95 \%, 4.1-35.2, \mathrm{p}<0.001)$. When analysing this association using a logistic regression model, Phl p 5 was the only allergen associated with the risk of being sensitised to profilin $(p=0.0023)$.
\end{abstract}

Conclusions: In patients sensitised to profilin, the concordance between SPT and CRD is much lower than in those not sensitised to profilin. CRD is able to provide refined information about which pollens increase the risk of sensitisation to profilin.

Keywords: Component-resolved diagnosis, Skin prick test, Profilin, Polysensitisation

\section{Background}

Immunoglobulin E (IgE)-mediated allergic diseases, mainly asthma and allergic rhinitis, are highly prevalent diseases, affecting hundreds of millions of people worldwide $[1,2]$. The inherent costs of these diseases, especially in developed countries, are extremely high [3,4]. Therefore, defining an adequate diagnostic strategy is

\footnotetext{
*Correspondence: Fernando.delatorremartinez@alk.net

${ }^{10}$ ALK-Abelló, S.A., C/Miguel Fleta, 19, 28037 Madrid, Spain

Full list of author information is available at the end of the article
}

crucial in order to establish the best therapeutic option and consequently, reduce the economic burden of allergic diseases. Until recently, the allergological diagnosis in clinical practice was mainly based on the IgE response against whole allergen extracts, either assessed by means of skin prick test (SPT) and/or by specific IgE (sIgE). However, the sensitisation profile of allergic patients in complex pollen areas reveals that most patients are polysensitised [5]. In these patients, the use of conventional techniques may result insufficient to establish an adequate diagnosis [6]. Recent studies have shown that 
frequently polysensitisation may be due to cross-reactivity caused by sensitisation to panallergens, such as profilin, polcalcin or lipid-transfer proteins $[7,8]$. Sensitisation to these molecules makes it difficult to discern whether a positive test to a whole extract, either by SPT or sIgE, is positive due to a primary sensitisation or a cross-reactivity phenomenon.

Component-resolved diagnosis (CRD) provides a more specific diagnosis in patients with positive IgE to multiple pollen allergens. The main outcome is to learn the sensitisation profile of allergic patients and consequently, to allow a more precise prescription of immunotherapy including only relevant allergens $[9,10]$.

Some of the aforementioned studies have been performed with patients from different geographical areas and consequently, with different sensitisation profiles as well as different allergen exposure. Therefore, extrapolating conclusions, although valid, may entail certain bias [5, 7]. In our study we have analysed allergic patients from one geographical area, with the aim of (a) establishing the sensitisation profiles in the selected area to the more prevalent aeroallergens by means of SPT and CRD as well as the differences in these profiles according to age, type of allergic respiratory disease and presence of plantfood allergy, (b) studying the differences between both diagnostic techniques in patients sensitised to the main panallergen in the area (profilin) and (c) in profilin-sensitised patients, establishing the risk-factors associated with being sensitised to profilin.

\section{Methods}

\section{Geographical area of study}

The study has been carried out in a geographical area (Aragon, Spain) with a continental Mediterranean climate with cold winters, dry and hot summers and with areas of high mountains (see Fig. 1).

\section{Patients}

Patients included in the study were selected consecutively for two periods in the same year before and after the pollen season. All patients had a clinical history of seasonal allergic rhinitis, rhinoconjunctivitis or asthma for at least 2 years, should not have received immunotherapy in the last 5 years, according to the same methodology used in previous studies $[5,7]$ and had to reside in the area of the study for 5 consecutive years or longer before being included in the study.

Clinical diagnosis of allergic rhinitis and asthma was performed according to international and national guidelines $[11,12]$.

Written informed consent was obtained from each patient before entering the study. In case of patients aged

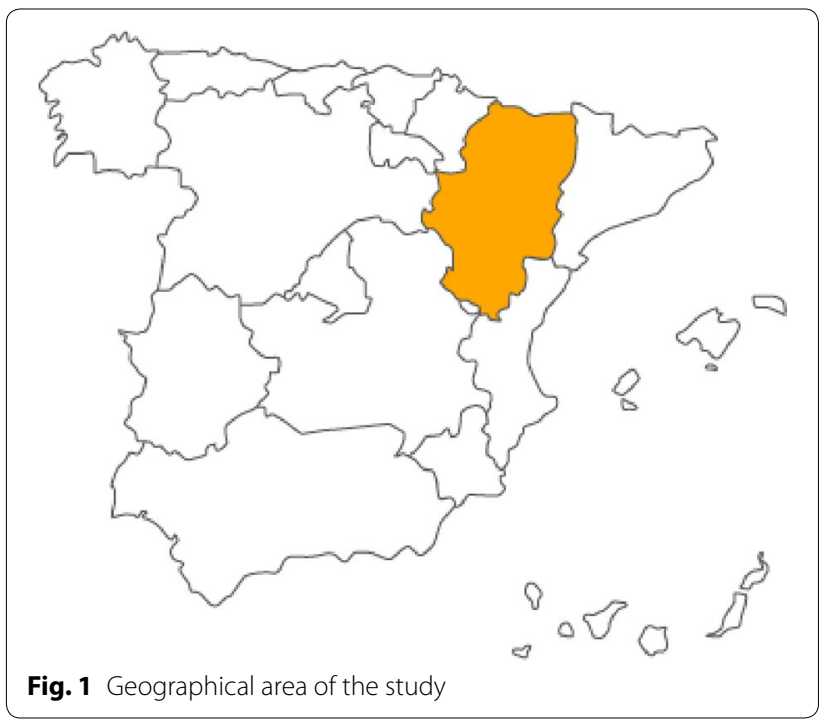

$<18$ years, informed consent of parents/guardians was also obtained. The study was approved by the regional ethical committee (Comité Etico de Investigación Clínica de Aragón).

Serum samples were collected from the subjects, stored at $-40{ }^{\circ} \mathrm{C}$ and thawed immediately before analysis.

\section{Skin prick test extracts}

Natural profilin, Pho d 2 extract, was prepared by purifying a date palm extract by affinity chromatography with a poly-L-proline-Sepharose. Purity (higher than $99 \%$ ) was checked by SDS-PAGE, mass spectrometry and amino acid analysis. The concentration of Pho $\mathrm{d} 2$ in the extract was $50 \mu \mathrm{g} / \mathrm{ml}$. Date palm polcalcin enriched extract was obtained from the same extract (showing total protein concentration of $500 \mu \mathrm{g} / \mathrm{ml}$ after Lowry) after removal of profilin. In a previous experiment, positive SPT responses to complete Palm tree extracts were assigned either to profilin or polcalcin sensitised patients, but not to LTPs, CCDs or Glucanases. Protein identity was assessed by SDS-PAGE. The concentration of polcalcin, measured by an inhibition assay against $r$-Che a 3 , was determined to be $1 \mu \mathrm{g} / \mathrm{ml}$.

A commercial peach extract from ALK-Abello S.A., adjusted to $30 \mu \mathrm{g} / \mathrm{ml}$ of Pru p 3, was shown to lack other relevant allergens (such as Pru p 1 and Pru p 4).

The other diagnostic extracts used in the study (Olea, grass-mix, Artemisia, Salsola, Cupressus, Parietaria, Platanus and Plantago) were complete commercial extracts from ALK-Abello S.A. at $30 \mathrm{HEP} / \mathrm{ml}$. Alternaria extract is standardised in $\mu \mathrm{g} / \mathrm{mL}$ of the major allergen Alt a 1 ( 25 $\mu \mathrm{g} / \mathrm{mL}$ ). These pollens were selected because they are the most prevalent sensitizing allergens in the area. 
Panel of purified allergens for slgE determination to major allergens

The panel of allergens included in the study were: $\mathrm{nPhl} p$ 1 and $\mathrm{nPhl}$ p 5, nOle e 1, nArt v 1, nCup s 1, nPar j 2, nPla a $1+2$, nPla $11, \mathrm{nSal} \mathrm{k} 1$. The panallergens studied were: nPho d 2 (profilin), rChe a 3 (polcalcin) and rPru p 3 (LTP). sIgE against Alt a 1 was also determined due to the clinical relevance of this allergen in the area, not studied in previous research [7] and also because the exposure to grass and Alternaria may be linked to severe asthma [24].

The manufacturing process of all these allergens has been previously described $[5,7,13]$.

Specific IgE to the different allergens was tested with the ADVIA Centaur ${ }^{\circledR}$ platform (Bayer HealthCare Diagnostics Division, Tarrytown, NY, USA). The principle of the sIgE assay is based upon a reverse sandwich assay and was performed according to previously established methods [14].

Specific IgE was considered positive when $\geq 0.35 \mathrm{kU} / \mathrm{l}$.

\section{Statistical methods}

In order to analyse qualitative variable association, Pearson's Chi square test was used when variables fitted all required assumptions and Fisher's exact test when not. A multivariate analysis by means of logistical regression by determination of the odds ratio was used to evaluate the level of risk of being sensitised to profilin.

\section{Results}

\section{Sample description}

A total of 231 patients were included in the study. Patients characteristics are described in Table 1. The mean (SD) age of patients was 22.6 (13.6) years, median (range): 18 (4-65) years. Despite food allergy not being an inclusion criterion, almost $20 \%$ of patients had allergic food reactions.

\section{Sensitisation profiles}

In Fig. 2a, b we can see the sensitisation rates by SPT and sIgE to major allergens. The statistically significant differences on the sensitisation profile according to demographic and clinical parameters studied are shown in Table 2.

The percentage of patients sensitised to Alternaria was $23 \%$ by SPT and $24 \%$ by sIgE to its major allergen Alt a 1.

\section{Comparison of results in patients sensitised to profilin}

Patients sensitised to profilin were sensitised to a higher number of allergen sources, when compared to profilinnegative patients; this was true, both for SPT (mean of 9 allergens vs. 5 allergens, $\mathrm{p}<0.0001$ ) and $\operatorname{sIgE}$ (mean of 4 allergens vs. 2 allergens, $\mathrm{p}<0.0001$ ). In both groups, the
Table 1 Characteristics of patients

\begin{tabular}{lc}
\hline & $\%$ \\
\hline Age & \\
$\leq 14$ years & 45.9 \\
$>14$ years & 54.1 \\
Sex & \\
Male & 49.1 \\
Female & 50.9 \\
Clinical diagnosis & \\
Rhinitis & 98.7 \\
Conjunctivitis & 81.8 \\
Asthma & 46.8 \\
Mild intermittent & 63.0 \\
Mild persistent & 25.9 \\
Moderate & 11.1 \\
Food allergy & 18.7 \\
Oral allergy syndrome (OAS) & 13.4 \\
Fruits & 5.2 \\
Nut & 3.5 \\
Fruits and nut & 3.0 \\
Seafood & 1.3 \\
Urticaria/angioedema & 7.8 \\
Fruits & 3.0 \\
Nut & 2.6 \\
Anaphylaxis & 1.3 \\
Asthma & 0.4 \\
\hline
\end{tabular}

relation between sensitization measured by SPT and by sIgE was studied by means of a study of cases (patients with positive sIgE to a specific allergen) and controls (patients with negative sIgE to the same allergen). The outcome, in terms of odds-ratios (OR), was statistically significant for Olea (Ole e 1), Salsola (Sal k 1) and Platanus (Pla a 1+2) (Table 3) indicating that concordance between both diagnostic techniques is much higher for patients not sensitised to profilin.

The risk of being sensitised to profilin was assessed for SPT and sIgE results. For SPT, different pollens are statistically associated with the risk of being sensitised to this panallergen (Olea $\mathrm{p}=0.04$, Grass $\mathrm{p}=0.0006$, Artemisia $\mathrm{p}=0.0135$, Salsola $\mathrm{p}=0.0044$, Platanus $\mathrm{p}<0.0001$ and Plantago $\mathrm{p}<0.0001)$. However, when this risk is analysed considering the $\operatorname{sgE}(>0.35 \mathrm{kU} / \mathrm{l})$ despite SPT, the only allergens associated with risk are Ole e 1 (OR 3.5, CI $95 \%, 1.6-7.6, \mathrm{p}=0.0014$ ), and Phl p 5 (OR 11.9, CI $95 \%$, 4.1-35.2, $\mathrm{p}<0001$ ). Applying a logistic regression model, the only allergen with a statistically significant risk is Phl p $5(\mathrm{p}=0.0023)$. Analysing this OR for different levels of sIgE to Phl p 5, the risk decreases but remains statistically significant (sIgE > $10 \mathrm{kU} / \mathrm{l}$ : OR 7.6, CI $95 \%$ : 3.335.2, p < 0001. sIgE > 50 kU/L: OR 5.2, CI $95 \%$ : 2.4-11.3, $\mathrm{p}<0001)$. 

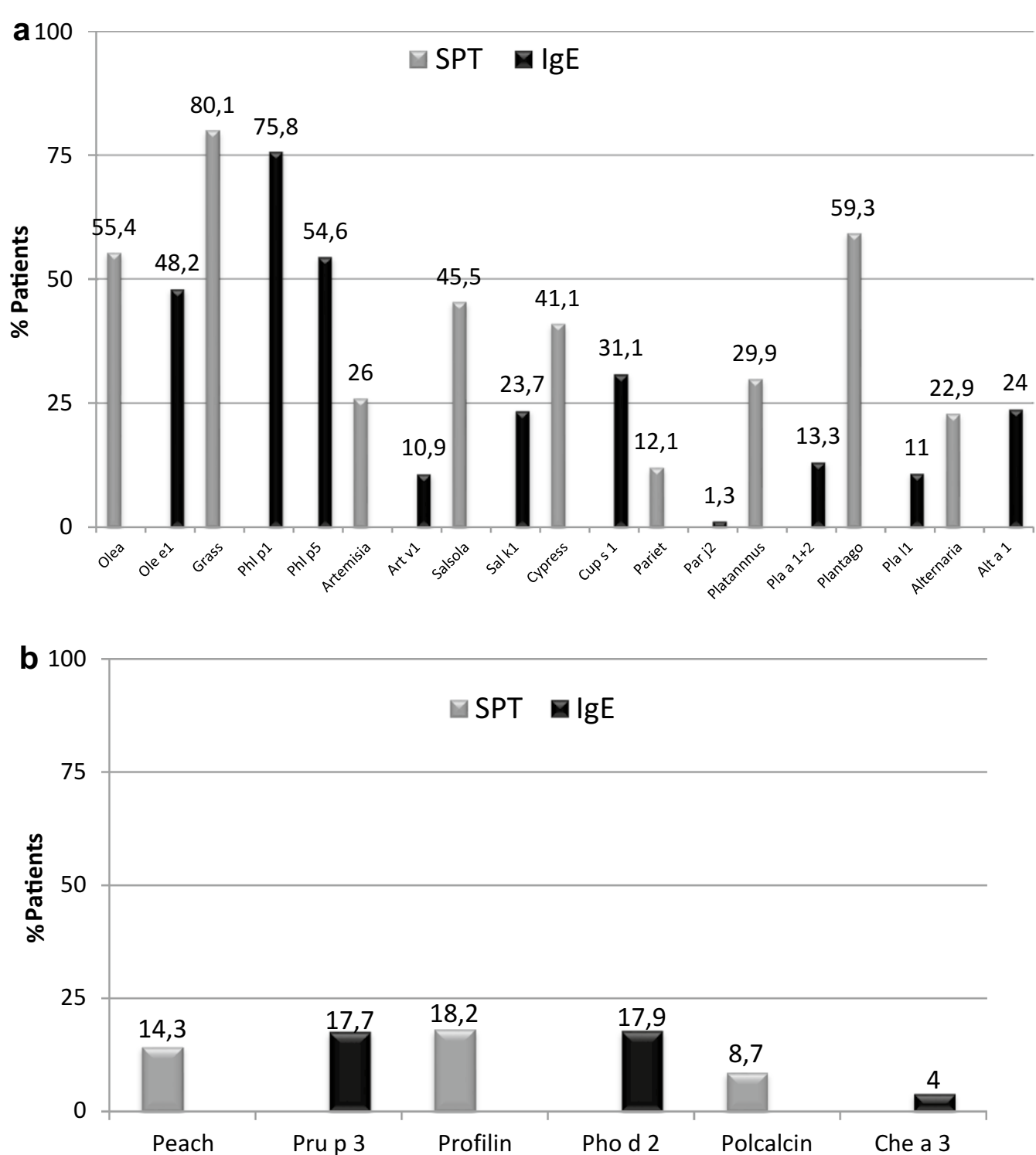

Fig. 2 Prevalence of major allergens measured by SPT and slgE, a Pollens and Alternaria, b panallergens

\section{Food allergy}

The presence of food allergy is associated with different allergens depending on the clinical reaction. Oral allergy syndrome (OAS) as the only clinical manifestation of food allergy was statistically associated with different allergens by SPT (Artemisia, $\mathrm{p}<0.0001$ : Parietaria, $\mathrm{p}=0.0121$ : Platanus, $\mathrm{p}=0.0045$, peach, $\mathrm{p}<0.0001$ and profilin, $\mathrm{p}=0.0290)$ and by $\operatorname{sIgE}(\mathrm{Phl} \mathrm{p} 5, \mathrm{p}=0.0478$ and Pru p 3, p $<0.0001$, being close to statistical significance for Art v 1, p = 0.0661 and Pho d 2, p = 0.0801). However, when the clinical manifestation of food allergy was more severe (urticaria, angioedema, anaphylaxis) the association for SPT results is only significant for
Artemisia $(\mathrm{p}=0.0118)$ and peach $(\mathrm{p}<0.0001)$ and by sIgE, only for Pru p $3(\mathrm{p}<0.0001)$.

\section{Discussion}

Nowadays, to perform a diagnostic workup of allergic diseases based only on conventional techniques such as SPT or sIgE to whole extracts may result insufficient in many patients. Allergic patients frequently present sensitisation to multiple allergens, both children [15] and adults, and it is not always possible to establish which allergens are positive due to genuine sensitization or which allergens are positive due to a phenomenon of cross-reactivity. CRD has been proposed by different authors $[9,16-20]$ as an essential 
Table 2 Differences on sensitisation profile according to demographic and clinical parameters

\begin{tabular}{llll}
\hline & \multicolumn{1}{l}{ Age } & p value \\
\cline { 2 - 3 } & $\mathbf{\leq 1 4}$ years & $\mathbf{> 1 4}$ years & \\
\hline SPT+ & 32.1 & 15.2 & \\
Alternaria & 32.1 & 48.8 & 0.0024 \\
$\begin{array}{l}\text { Cupressus } \\
\text { Polcalcin }\end{array}$ & 16 & 25.6 & 0.0100 \\
slgE+ & 35 & & 0.0498 \\
Alt a 1 & 19.4 & 14.8 & \\
Cup s 1 & Sex & 40.7 & 0.0004 \\
\cline { 2 - 3 } & Male & & 0.0006 \\
\hline
\end{tabular}

\begin{tabular}{llll}
\hline $\begin{array}{c}\text { SPT+ } \\
\text { Peach } \\
\text { slgE+ } \\
\text { Prup 3 }\end{array}$ & 35 & 14.8 & 0.0034 \\
\hline & 60.9 & 9.1 & $<0.0001$ \\
\hline & Asthma & \\
\cline { 2 - 3 } & Yes & No & \\
\hline
\end{tabular}

\begin{tabular}{llll}
\hline slgE + & & & \\
Sal k 1 & 16.2 & 30.1 & 0.0139 \\
\hline & Food allergy: OAS & \\
\cline { 2 - 3 } & Yes & No
\end{tabular}

\begin{tabular}{lllr}
\hline SPT+ & & & \\
Artemisia & 58.1 & 21 & $<0.0001$ \\
Parietaria & 26.8 & 10 & 0.0121 \\
Platanus & 51.6 & 26.5 & 0.0045 \\
Peach extract & 45.2 & 9.5 & $<0.0001$ \\
Profilin & 32.3 & 16 & 0.0290 \\
slgE+ & & & 0.0478 \\
Phl p 5 & 64.5 & 45.4 & $<0.0001$ \\
Prup 3 & 54.8 & 11.8 & \\
\hline & Food allergy: systemic reactions & \\
& (no OAS) & & \\
\cline { 2 - 3 } & Yes & No &
\end{tabular}

SPT+

\begin{tabular}{lrrr} 
Artemisia & 58.1 & 23.6 & 0.0118 \\
Peach extract & 61.3 & 9.1 & $<0.0001$ \\
slgEt & & & \\
Prup 3 & 69.6 & 11.8 & $<0.0001$ \\
\hline
\end{tabular}

The figures correspond to percentage of patients with a positive test (SPT or slgE). Only statistical significant results are displayed

OAS oral allergy syndrome

diagnostic tool, not only for establishing the sensitisation profile of patients but also because it may aid in selecting the most adequate composition of allergen immunotherapy.
Many recent publications have pointed out the role of panallergens as a confusion factor for the correct diagnosis of allergic sensitization $[5,7,8,21]$. Therefore, the diagnostic algorithm in complex allergen areas must take into account the sensitisation (or not) to these allergens. Several diagnostic algorithms have been proposed [7, 9].

In this study, when we compare the adult and paediatric populations, we see that both conventional diagnostic techniques and CRD perform similarly. Alternaria sensitization is more prevalent in children than in adults, both by SPT and CRD. Previous studies, or studies in which sensitisation to Alternaria is a risk factor in the adult population for severe asthma [23], have shown that humidity and fungi such as Alternaria are associated with a greater sensitisation rate in the infant population aged 5-6 years [22]. In this study, this kind of association was not observed, probably due to the type of patient included.. Only sensitisation to Sal k 1 appears to be associated with a distinct clinical expression, being more prevalent in patients with rhinitis than in those with asthma. Differences were observed between results obtained by SPT and those obtained by CRD in patients with food allergy. Whereas there are different allergens associated with the presence of OAS by SPT, probably due to the presence of lipid-transfer proteins (LTPs) in these extracts, by CRD we see that OAS is associated with sensitisation to two allergens (Phl p 5 and Pru p 3), while severe reactions are associated exclusively with Pru p 3 . The model of patients with pollinosis and food allergy is complex, although its study allows us to gain insight to some characteristics of allergic sensitization and clinical reactivity.

The confounding effect of sensitisation to profilin on the interpretation of diagnostic techniques has already been highlighted in previous studies conducted according to a methodology similar to our own $[5,7]$. Through a case-control study, we can see that in patients sensitised to the major allergens of Olea, Salsola and Platanus, the concordance of SPT and CRD is much greater in the absence of profilin sensitization. In the case of sensitisation to Phl p 5, the differences were almost statistically significant $(p=0.067)$; no significant differences were recorded for the remaining allergens. These results may indicate that profilin sensitization is related with the most prevalent pollens in the area of study, and consequently with higher clinical relevance, excluding Plantago (high prevalence by SPT but low prevalence of sensitization to its major allergen Pla 1 1) and Cupressus. The lack of relation between sensitization to cypress-pollen and profilin has been previously observed [25]. When assessing the risk of sensitisation to profilin, by SPT, multiple allergens are associated with this risk (grass, Olea, Salsola, Artemisia, Platanus and Plantago) and it is difficult 
Table 3 Relation between allergens measured by SPT and allergens measured by slgE in patients with positive slgE to Pho d 2 (profilin+) versus negative slgE to Pho d 2 (profilin-)

\begin{tabular}{|c|c|c|c|c|c|c|c|c|c|c|c|}
\hline & \multicolumn{8}{|c|}{ Allergen } & \multirow[t]{4}{*}{ OR } & \multirow[t]{4}{*}{ Cl $95 \%$} & \multirow[t]{4}{*}{$p$ value } \\
\hline & \multicolumn{4}{|c|}{ Ole e $1+$} & \multicolumn{4}{|c|}{ Ole e $1-$} & & & \\
\hline & \multicolumn{2}{|c|}{ SPT Olea+ } & \multicolumn{2}{|c|}{ SPT Olea- } & \multicolumn{2}{|c|}{ SPT Olea+ } & \multicolumn{2}{|c|}{ SPT Olea- } & & & \\
\hline & $\mathbf{n}$ & $\%$ & $\mathbf{n}$ & $\%$ & $\mathrm{n}$ & $\%$ & $\mathrm{n}$ & $\%$ & & & \\
\hline Pho d 2+ & 24 & 88.9 & 8 & 66.7 & 3 & 11.1 & 4 & 33.3 & 4.0 & $21.8-0.73$ & 0.0005 \\
\hline \multirow{4}{*}{ Pho d 2- } & 66 & 97.1 & 22 & 19.5 & 2 & 2.9 & 91 & 80.5 & 136.5 & 600.7-31.0 & \\
\hline & \multicolumn{4}{|c|}{ Sal k 1+ } & \multicolumn{4}{|c|}{ Sal k 1- } & & & \\
\hline & \multicolumn{2}{|c|}{ SPT Sal+ } & \multicolumn{2}{|c|}{ SPT Sal- } & \multicolumn{2}{|c|}{ SPT Sal+ } & \multicolumn{2}{|c|}{ SPT Sal- } & & & \\
\hline & $\mathbf{n}$ & $\%$ & $\mathrm{n}$ & $\%$ & $\mathrm{n}$ & $\%$ & $\mathrm{n}$ & $\%$ & & & \\
\hline Pho d 2+ & 11 & 84.6 & 17 & 63.0 & 2 & 15.4 & 10 & 37.0 & 3.2 & $17.7-0.6$ & 0.0118 \\
\hline \multirow[t]{4}{*}{ Pho d 2- } & 38 & 92.7 & 35 & 24.5 & 3 & 7.3 & 108 & 75.5 & 39.1 & $134.5-11.4$ & \\
\hline & \multicolumn{4}{|c|}{ Pla a $1+2+$} & \multicolumn{4}{|c|}{ Pla a $1+2-$} & & & \\
\hline & \multicolumn{2}{|c|}{ SPT Pla+ } & \multicolumn{2}{|c|}{ SPT Pla- } & \multicolumn{2}{|c|}{ SPT Pla+ } & \multicolumn{2}{|c|}{ SPT Pla- } & & & \\
\hline & $\mathrm{n}$ & $\%$ & $\mathrm{n}$ & $\%$ & $\mathrm{n}$ & $\%$ & $n$ & $\%$ & & & \\
\hline Pho d 2+ & 3 & 60 & 26 & 74.3 & 2 & 40 & 9 & 25.7 & 0.5 & $3.6-0.07$ & 0.0372 \\
\hline Pho d 2- & 11 & 45.8 & 26 & 16.4 & 13 & 54.2 & 133 & 83.6 & 4.3 & $10.7-1.8$ & \\
\hline
\end{tabular}

OR odds-ratio, $C l$ confidence interval. Sal: Salsola. Pla: Platanus

$p$ value: Breslow-Day test for OR homogeneity

to establish which one is the culprit pollen. However, when we determine this risk measuring the sensitisation to major allergens by means of CRD, the association is only statistically significant for the two more prevalent allergens: Ole e 1 and Phl p 5. However, unlike in other studies where there are areas with very high grass allergen concentrations [5], the risk of sensitisation to profilin not only increases in line with IgE values, which, in turn, increase in response to $\mathrm{Phl} \mathrm{p} \mathrm{5,} \mathrm{but} \mathrm{the} \mathrm{OR} \mathrm{value} \mathrm{actu-}$ ally decreases. This difference is probably attributable to the fact that grasses are the most prevalent allergen in the area studied, though there are other allergens (Olea, Salsola and Cupressus) that are also relevant where there is no one visibly dominant pollen.

\section{Conclusion}

Panallergen sensitization is a major confounder factor when using conventional diagnostic techniques (whole extract SPT or sIgE). CRD is an essential tool for determining the risk-factors associated with panallergen sensitisation, allowing to overcome these pitfalls.

\section{Authors' contributions}

All the authors have participated in the patients' inclusion (except $L$ and FT) as well as in the elaboration of this manuscript. All authors read and approved the final manuscript.

\section{Author details}

${ }^{1}$ Hospital Clínico Universitario, Saragossa, Spain. ${ }^{2}$ Consorcio de Salud de Aragón, Huesca, Spain. ${ }^{3}$ Private Office, Huesca, Spain. ${ }^{4}$ Hospital Royo Villanova, Saragossa, Spain. ${ }^{5}$ Hospital Miguel Servet, Saragossa, Spain. ${ }^{6}$ Consorcio de Salud de Aragón, Saragossa, Spain. ${ }^{7}$ Hospital Militar, Saragossa, Spain. ${ }^{8}$ Hospital Obispo Polanco, Teruel, Spain. ${ }^{9}$ Policlínica Sagasta, Saragossa, Spain.

${ }^{10}$ ALK-Abelló, S.A., C/Miguel Fleta, 19, 28037 Madrid, Spain.

\section{Acknowledgements}

Juan Dorado (Pertica, Madrid, Spain) for the statistical analysis and his technical support and Agustín Galán for the serum sample analysis.

\section{Competing interests}

All the authors have participated as members of ALERGOARAGON (Sociedad Aragonesa de Alergia). The study has been partially supported by ALK-Abelló, S.A. LJ and FT are employees of ALK-Abelló, S.A.

Received: 30 January 2016 Accepted: 26 May 2016

Published online: 29 June 2016

\section{References}

1. Asher MI, Montefort S, Björsten B, Lai CK, Strachan DP, Weiland SK, Williams H, ISAAC Phase Three Study Group. Worldwide time trends in the prevalence of asthma, allergic rhinoconjunctivitis, and eczema in childhood: ISAAC phases one and three repeat multicountry cross-sectional surveys. Lancet. 2006;368:733-43.

2. Burney PG, Luczynska C, Chinn S, Jarvis D. The European Community Respiratory Health Survey. Eur Respir J. 1994;7:954-60.

3. Reed SD, Lee TA, McCrory DC. The economic burden of allergic rhinitis: a critical evaluation of the literature. Pharmacoeconomics. 2004;22:345-61. 
4. Lozano P, Sullivan SD, Smith DH, Weiss KB. The economic burden of asthma in US children: estimates from the national medical expenditure survey. J Allergy Clin Immunol 1999;104:957-63.

5. Barber D, de la Torre F, Feo F, Florido F, Guardia P, Moreno C, Quiralte J, Lombardero M, Villalba M, Salcedo G, Rodríguez R. Understanding patient sensitization profiles in complex areas: a molecular epidemiological study. Allergy. 2008;63:1550-8.

6. Vidal C, Enrique E, Gonzalo A, Moreno C, Tabar Al, of behalf of Expert Clinical Participants. Diagnosis and allergen immunotherapy treatment of polysensitized patients with respiratory allergy in Spain: an allergists' consensus. Clin Transl Allergy. 2014:4:36.

7. Barber D, de la Torre F, Lombardero M, Antépara I, Colás C, Dávila I, Tabar Al, Vidal C, Villalba M, Salcedo M, Rodríguez R. Component-resolved diagnosis of pollen allergy based on skin testing with profilin, polcalcin and lipid transfer protein pan-allergens. Clin Exp Allergy. 2009;39:1764-73.

8. Hauser M, Roulias A, Ferreira F, Egger M. Panallergens and their impact on the allergic patient. Allergy Asthma Clin Immunol. 2010;6:1.

9. Douladiris N, Savatianos S, Roumpedaki I, Skevaki C, Mitsias D, Papadopoulos NG. A molecular diagnostic algorithm to guide pollen immunotherapy in Southern Europe: towards component-resolved management of allergic diseases. Int Arch Allergy Immunol. 2013;162:163-72.

10. Luengo O, Cardona V. Component resolved diagnosis: when should it be used? Clin Transl Allergy. 2014;4:28.

11. Bousquet J, Khaltaev N, Cruz AA, Denburg J, Fokkens WJ, Togias A, Zuberbier T, et al. Allergic rhinitis and its impact of asthma (ARIA) 2008 update (in collaboration with the World Health Organization, GA ${ }^{2}$ LEN and AllerGen). Allergy. 2008;63(Suppl. 86):8-160.

12. Plaza $V$, et al. GEMA (Guía española para el manejo del asma). Arch Bronconeumol. 2009;45(Supl7):2-35.

13. Barber D, Arias J, Boquete M, Cardona V, Carrillo T, Gala G, Gamboa P, García-Robaina JC, Hernández D, Sanz ML, Tabar Al, Vidal C, Ipsen H, de la Torre F, Lombardero M. Analysis of mite allergic patients in a diverse territory by improved diagnostic tools. Clin Exp Allergy. 2012;42:1129-38.

14. Petersen $A B$, Gudmann P, Milvang-Groenager $P$, Moerkeberg $R$, Boegestrand S, Linneberg A, Johansen N. Performance evaluation of a specific IgE assay developed for the Advia Centaur immunoassay system. Clin Biochem. 2004;37:882-92.

15. Feliu A, González de Olano D, González E, Rodríguez B, Ruiz-Hornillos J, Jimeno $L$, de la Torre F. on behalf of the ESPLORA group. A multicenter study of sensitization profiles in an allergic pediatric population in an area with high allergen exposure. J Investig Allergol Clin Immunol. 2013;23:337-44.

16. Darsow U, Brockow K, Pfab T, Jakob T, Petersson CJ, Borres MP, Ring J, Behrendt H, Huss-Marp J. Heterogeneity of molecular sensitization profiles in grass pollen allergy-implications for immunotherapy? Clin Exp Allergy. 2010;4(44):778-86.

17. Stringari G, Tripodi S, Caffarelli C, Dondi A, Asero R, Di Rienzo A, et al. The effect of component-resolved diagnosis on specific immunotherapy prescription in children with hay fever. J Allergy Clin Immunol. 2014:134:75-81.

18. Moreno C, Justicia JL, Quiralte J, Moreno-Ancillo A, Iglesias-Cadarso A, Torrecillas M, Labarta N, García MA, Dávila I. Olive, grass or both? Molecular diagnosis for [sic: the] allergen immunotherapy selection in polysensitized pollinic patients. Allergy. 2014;69:1357-63.

19. Valenta R, Twaroch T, Swoboda I. Component-resolved diagnosis to optimize allergen-specific immunotherapy in the Mediterranean area. J Investig Allergol Clin Immunol. 2007;17(suppl1):36-40.

20. Sastre J, Landivar ME, Ruiz-García M, Andregnette-Rosigno MV, Mahillo I. How molecular diagnosis can change allergen-specific immunotherapy prescription in a complex pollen area. Allergy. 2012;67:709-11.

21. Orovitg A, Guardia P, Barber D, de la Torre F, Rodríguez R, Villalba M, Salcedo G, Monteseirin J, Conde J. Enhanced diagnosis of pollen allergy using specific immunoglobulin E determination to detect major allergens and panallergens. J Investig Allergol Clin Immunol. 2011;21:253-9.

22. Schäfer T, Krämer U, Dockery D, Vieluf D, Behrendt H, Ring J. What makes a child allergic? Analysis of risk factors for allergic sensitization in preschool children from East and West Germany. Allergy Asthma Proc. 1999;20:23-7.

23. Zureik M, Neukirch C, Leynaert B, Liard R, Bousquet J, Neukirch F. Sensitization to airborne moulds and severity of asthma: cross sectional study from European Community Respiratory Health Survey. BMJ. 2002;325:411-21.

24. Kim HK, Lund S, Baum R, Rosenthal P, Khorram N, Doherty TA. Innate type 2 response to Alternaria extract enhances ryegrass-induced lung inflammation. Int Arch Allergy Immunol. 2014;163:92-105.

25. Asero R, Monsalve R, Barber D. Profilin sensitization detected in the office by skin prick test: a study of prevalence and clinical relevance of profilin as a plan food allergen. Clin Exp Allergy. 2008;38:1033-7.

\section{Submit your next manuscript to BioMed Central and we will help you at every step:}

- We accept pre-submission inquiries

- Our selector tool helps you to find the most relevant journal

- We provide round the clock customer support

- Convenient online submission

- Thorough peer review

- Inclusion in PubMed and all major indexing services

- Maximum visibility for your research

Submit your manuscript at www.biomedcentral.com/submit
BioMed Central 